\title{
Nunca es tarde...Argentina tiene finalmente su legislación sobre arbitraje
}

\author{
Daniel Alejandro Casella*
}

SUMARIO: 1. Introducción. Las discusiones sobre el trámite legislativo 2. Las modificaciones más trascendentes. 2.1. El arbitraje como contrato. 2.2. La forma. El acuerdo arbitral. 2.3. Materias excluidas. 2.4. El arbitraje de equidad y de derecho. 2.5. La autonomía del acuerdo arbitral. La competencia de los árbitros. 2.6. Medidas cautelares. 2.7. La remisión al arbitraje. La revisión judicial. 2.8. Arbitraje Institucional-Ad Hoc. 2.9. Los árbitros. 3. Conclusión.

\section{Introducción. Las discusiones sobre el trámite legislativo}

El Código Civil Argentino, que redactó Dalmacio Vélez SARsfield, fue tratado a libro cerrado, en un proceso que comenzó con el envío por parte del Poder Ejecutivo Nacional el 25 de agosto de 1869 y, luego de pasar por ambas Cámaras, se promulgó el 29 de setiembre del mismo año. Dicho Código se mantuvo inalterable por ciento cincuenta años, salvo una significativa reforma -más por su calidad que por la cantidad de artículos involucrados $^{1}$ - realizada en 1968 (Ley 17.711), por obra de GuILLERMo Borda, que significó un adelanto muy importante en el derecho privado ${ }^{2}$.

*Socio de Casella \& Hilal, Ciudad de Buenos Aires, Argentina. Profesor Adjunto Ordinario de la Universidad Argentina de la Empresa (UADE), Argentina. Las opiniones vertidas en el presente trabajo son exclusiva responsabilidad del autor.

1. Según Riviera la puesta en vigencia de la Ley 17.711 que modificó sólo el 10\% del articulado del Código Civil, causó una gran litigiosidad y variada jurisprudencia que incluye plenarios de la cámara Civil de la Capital, de la Cámara Civil y Comercial de La Plata, etc. Según este autor no hay que ser muy imaginativo para prever que la aplicación de todo el CCyC, que sustituye al Código Civil y al Código de Comercio, ha de producir el mismo efecto multiplicado al infinito (Ver J. Rivera, "Instituciones de Derecho Civil - Parte General", Abeledo Perrot, 6a edición, t. I, no 205 y ss., a partir de p. 243).

2. Como señalaban Alterint y Alegría, con la sanción de la Ley 17.711 "fueron incorporados al Código Civil principios propios de los contratos comerciales: la doctrina de la apariencia, la fuerza jurígena de los usos, las interpretaciónes conforme a la buena fe-probidad, la mora automática, cláusula resolutoria tácita; más tarde el anatocismo fue admitido por la Ley 23.928. El concurso de los no comerciantes fue sometido igual procedimiento que el aprobado para los comerciantes (Art. 2, Ley 24.522) y fue sujeto también al juez mercantil (Art. 43 bis. Decreto-Ley 1285/58, según Ley 22.903)” (ALTERINI y ALEGRIA, “Unificación sustancial del derecho civil y el derecho comercial', LA LEY, 2011-F, 886). 
El arbitraje en Argentina fue regulado básicamente como una materia procesal ${ }^{3}$ y se carecía de una ley de arbitraje interna. Cada Código Procesal Provincial contiene una regulación propia de la materia ${ }^{4}$, toda vez que en Argentina la legislación procesal constituye materia no delegada en el Gobierno Federal, y por ello reservada a las provincias ${ }^{5}$.

Esta disparidad de normas lleva necesariamente a cierta confusión, aunque es oportuno aclarar que en general las normas procesales provinciales coinciden con las del Código Procesal Civil y Comercial de la Nación, que son aplicables a la capital de la nación y en la competencia federal. Con la falta de definición y claridad autores como Caviano y AguiLar han llamado la atención sobre el significativo retraso de la legislación argentina sobre arbitraje $^{6}$. Más aún si se tiene en cuenta la ratificación de tratados internacionales que incluyen al arbitraje como forma alternativa de resolución de controversias ${ }^{7}$. La demora de la Argentina en sancionar una ley de arbitraje propia era insostenible.

3. J. RiverA, El Arbitraje en Argentina, Revista de Derecho Comparado No. 11, Rubinzal Culzoni, 2005, p. 1.

4. El primer Código de Procedimientos en materia civil y comercial que rigió en el ámbito de la Justicia Nacional fue el que había sido sancionado en 1880 para la Provincia de Buenos Aires, que se adoptó como propio para la Capital Federal por Ley 1893 en 1886. La reforma integral del Código de 1967 (Ley 17.454) alcanzó también a las normas sobre arbitraje, aunque no hubo modificaciones sustantivas. Las reformas posteriores más importantes sufridas por el Código Procesal (Leyes 22.434 de 1981 y 25.488 de 2001) ni siquiera modificaron la redacción de las normas sobre arbitraje. El artículo 10 del CPCCN, que determina en qué casos la competencia de los tribunales nacionales es prorrogable a favor de árbitros o jueces extranjeros, sí fue modificado varias veces, en un clásico movimiento pendular: la Ley 17.454 estableció la prohibición de prorrogar la jurisdicción en favor de árbitros o jueces extranjeros, dejando de lado las disposiciones permisivas contenidas en la legislación anterior. Esta disposición fue modificada, en 1976, por la Ley 21.305, que admitió la prórroga bajo dos condiciones: que no se tratase de casos sometidos a la jurisdicción exclusiva de los jueces argentinos y que el acuerdo de voluntades que dispusiera la prórroga de jurisdicción fuese, en todos los casos, anterior a los hechos que motivaban la intervención de los jueces o árbitros. En 1981, la Ley 22.434 dio a la norma la redacción actual: la prórroga no solo puede ser acordada antes de los hechos que den origen a la controversia sino en cualquier tiempo, quedando solamente como excepciones los casos regidos por normas especiales de tratados internacionales, las prohibiciones legales y la jurisdicción argentina exclusiva.

5. Constitución Nacional de la República Argentina, Art. 121. La Constitución Argentina dispone que el derecho de fondo, sustancial, es nacional y que por ello, el Congreso Nacional tiene la atribución de dictar los Códigos civil, comercial, penal, de minería y de trabajo pero que, el dictado de las normas procesales es facultad no delegada por las Provincias en el Gobierno Nacional (Art.121 CN), razón por la cual los Códigos de fondo no han de alterar las jurisdicciones locales, correspondiendo su aplicación a los tribunales federales o provinciales según que las cosas o las personas cayeren bajo sus respectivas jurisdicciones (Art. 67, inc. 11 de la Constitución de 1853; corresponde al Art. 75, inc. 12 CN actual).

6. J. R. CAIVANO, "Argentina necesita mejorar su legislación sobre arbitraje”, Revista. La Ley.1994-A-994; F. AgUilar, "¿Para qué sirve una ley nacional de arbitraje?", La ley 20/01/2005, p. 1, AR/DOC/42/2005.

7. De los numerosos tratados celebrados por la Argentina cabe destacar por su alcance general la Convención de Nueva York de 1958, el Tratado Interamericano de Panamá de 1975, y dentro del ámbito restringido al MERCOSUR los Protocolos de Las Leñas (1992) y Buenos Aires (1998). En materia de protección de inversiones extranjeras Argentina ha celebrado tratados bilaterales (BIT por Bilateral Investment Treaty) en los que se incluye el arbitraje con más de 50 países bajo el paraguas de la Convención de Washington (Centro Internacional de Arreglos de Disputas de Inversiones o CIADI) de 1966. 
Esto es así, sin perjuicio de varios proyectos presentados por -o a iniciativa de- Jorge R. VANOssi para adoptar como legislación sobre arbitraje comercial internacional el texto de la Ley Modelo de UNCITRAL ${ }^{8}$; en los últimos años se han presentado al menos cuatro anteproyectos de Ley de Arbitraje, ninguno de los cuales ha tenido, finalmente, tratamiento parlamentario pleno, aunque algunos de ellos lograron ser tratados en Comisión: i) El Anteproyecto elaborado por la comisión de juristas creada por Decreto 958/1991, fue elevado originariamente por el Poder Ejecutivo al Congreso mediante Mensaje 2278 del 31 de octubre de 1991 y reiterado luego, con ligeras variantes, por Mensaje 726 del 22 de mayo de 1995; ii) El Anteproyecto elaborado por la comisión de juristas creada por Resolución del Ministerio de Justicia N 338/1998, fue elevado por el Poder Ejecutivo al Congreso a través del Mensaje 577 del 28 de mayo de 1999; iii) El Anteproyecto elaborado por la comisión consultiva creada por Resolución del Ministerio de Justicia y Derechos Humanos N0 219/2001, fue presentado al Congreso mediante Mensaje del Poder Ejecutivo N0 201/2002; iv) El Anteproyecto elaborado por el Dr. Sergio Villamayor Alemán en el marco del Convenio de Reforma Judicial, del que fueron parte representantes de la Corte Suprema, del Colegio de Abogados de la Ciudad de Buenos Aires y de varias entidades públicas y privadas, fue elevado por el Poder Ejecutivo en el año 2007 y, luego de haber perdido estado parlamentario, fue nuevamente presentado en el curso del año 2010.

Mientras tanto, varios países de Latinoamérica adoptaron en los últimos años una ley de arbitraje propia ${ }^{9}$. En efecto, Bolivia aprobó la Ley No 1770 sobre Arbitraje y Conciliación el 10 de marzo de 1997 (Ley No 1770); Brasil aprobó la Ley de Arbitraje No 9307 el 23 de septiembre de 1996 (Ley No 9307); Chile aprobó la Ley No 19.971 el 29 de septiembre de 2004 (Ley

8. Al menos en cuatro oportunidades, en los años 1991, 1996, 1999 y 2001. Ver, A. PIAGGI, "Evoluciones recientes del arbitraje comercial internacional en Latinoamérica”, en A. PIAGgi, y L. Estoup, (Dir.), Derecho Mercantil Contemporáneo, ed. La Ley, 2001, pp. 81 y ss.

9. Latinoamérica no es la única región donde el arbitraje ha evolucionado. La tendencia a la unificación de las leyes de arbitraje es notable en el mundo contemporáneo. En abril de 2001, la Ley Modelo ya había sido adoptada por más de treinta y ocho países. Se han promulgado leyes basadas en la Ley Modelo de la CNUDMI sobre arbitraje comercial internacional en Alemania, Australia, Azerbaiyán, Bahrein, Belarús, Bermudas, Bulgaria, Canadá, Chipre, Croacia, Egipto, dentro del Reino Unido de Gran Bretaña e Irlanda del Norte: Escocia, la Federación de Rusia, Grecia, Guatemala, Hong Kong (Región Administrativa Especial de China), Hungría, India, Irán (República Islámica del), Irlanda, Jordania, Kenya, Lituania, Madagascar, Malta, México, Nigeria, Nueva Zelanda, Omán, Paraguay, Perú, República de Corea, Macao (Región administrativa especial de China), Singapur, Sri Lanka, Túnez, Ucrania; Zambia, y Zimbabwe, dentro de los Estados Unidos de América: California, Connecticut, Illinois, Oregon y Texas (http://www.uncitral.org/sp-index.htm). Además de los nombrados Bolivia (Ley n 1770/1997) y Brasil (Ley 9307/1996) adoptaron sendas leyes de arbitraje. 
No19.971); Colombia aprobó el Decreto No 1818 el 7 de septiembre de 1998, el cual compila todas las normas aplicables a la Conciliación y el Arbitraje antes contenidas en diversas legislaciones (Decreto No 1818); Costa Rica aprobó el Decreto Ley No 7727, que contiene la Ley para los Métodos Alternativos de Solución de Disputas y la Promoción de la Paz del 4 de diciembre de 1997 (Decreto Ley No 7727); Ecuador aprobó la Ley de Arbitraje y Mediación del 24 de agosto de 1997, bajo el Registro Oficial No 145 del 4 de septiembre de 1997 (Ley bajo Registro Oficial No 145); Guatemala aprobó el Decreto Ley No 67-95, que contiene la Ley de Arbitraje del 17 de noviembre de 1995 (Decreto Ley No 67-95); Honduras aprobó el Decreto Ley No 161-2.000 que contiene la Ley de Conciliación y Arbitraje el 17 de octubre de 2.000 (Decreto Ley No 161-2.000); Panamá aprobó el Decreto Ley No 5 de 1999, que contiene la Ley de Arbitraje (Ley No 5); Perú aprobó la Ley No 26.572, que contiene la Ley General de Arbitraje el 6 de enero de 1996 (Ley No 26.572); Paraguay recientemente aprobó la ley No 1879 para el Arbitraje y la Mediación del 24 de abril 2.002 (Ley No 1.879); y finalmente, Venezuela aprobó la Ley sobre Arbitraje Comercial el 7 de abril de 1998 (Ley sobre Arbitraje Comercial). Aunque, técnicamente, no puede considerarse una "ley de arbitraje", hasta Cuba, en el año 2007, dictó el Decreto-Ley $\mathrm{N}^{\circ} 250$ que regula el funcionamiento de la "Corte Cubana de Arbitraje Comercial Internacional" y que recoge algunos principios de las modernas legislaciones sobre la materia ${ }^{10}$.

En cuanto a la legislación argentina, el Proyecto de Código Civil y Comercial de la Nación fue elaborado por una comisión integrada por el Presidente de la Corte Suprema de Justicia de la Nación, doctor Ricardo Luis Lorenzetti, como Presidente, la Ministro del mismo tribunal, doctora Elena Highton de Nolasco y la ex miembro de la Corte Suprema de la Provincia de Mendoza, la doctora Aída Kemelmajer de Carlucci (designada por el Decreto 191/2011).

Esta Comisión consultó a más de noventa profesores de todas las universidades públicas y privadas del país, quienes dieron su opinión por escrito y fueron tenidas en cuenta en la redacción final.

10. C. CONEJERo Roos, La influencia de la Ley Modelo de la CNUDMI Sobre Arbitraje Comercial Internacional en América Latina: Un Análisis Comparativo, Revista Chilena de Derecho, Vol. 32 N0 1, pp. 89 - 138 (2005). 
El proyecto fue presentado al Poder Ejecutivo con fecha 27 de marzo de 2012 y luego hubo un proceso de revisión por parte del Ministerio de Justicia que le introdujo modificaciones.

En efecto, elevado el proyecto al Congreso de la Nación por nota del día 7 de junio de 2012, fue analizado por la Comisión Bicameral para la Reforma, Actualización y Unificación de los Códigos Civil y Comercial de la Nación (CCyC), creada al afecto e integrada por legisladores de ambas Cámaras y procedentes de diferentes fuerzas políticas. Dicha comisión; llevó adelante audiencias públicas a lo largo de todo el país, con el objeto de recoger opiniones, observaciones y sugerencias, y se recibieron más de mil ponencias procedentes de todos los sectores sociales.

Ese anteproyecto, con reformas introducidas en el Congreso de la Nación a propuesta del Poder Ejecutivo de la Nación, se convirtió en la Ley 26.994, a regir a partir del primero de agosto de $2015^{11}$.

En el marco de esta verdadera recodificación se incorpora la regulación del Contrato de Arbitraje en el Capítulo 29 (artículos 1649 a 1665) dentro de los contratos en particular. Es decir que la novedad es la regulación del "contrato de arbitraje" (que incluye tanto el celebrado por las partes como el que resulta entre aquellas y los árbitros).

Es importante señalar que el CCyC parece legislar al instituto del arbitraje sin distinguir su carácter nacional o internacional ${ }^{12}$.

11. Es oportuno aclarar al lector que la nueva codificación no incluye a la Ley de Concursos y Quiebras, la de Sociedades comerciales (que ha sufrido algunas modificaciones muy discutibles pero no en forma integral), Ley de Seguros, la de Mercado de Capitales, la de Entidades financieras, la de Letra del Cambio, Vales y Pagaré, y la Ley de Cheques, entre otras.

12. La República Argentina posee normas sobre arbitraje internacional en el derecho convencional, los Tratados de Derecho Procesal internacional de Montevideo de 1889 y 1940, pero exclusivamente sobre temas puntuales. El Código Procesal trata excepcionalmente el arbitraje Internacional (Art. 519 bis) y el resto de la normativa (lib. VI, tít. I) es relativamente inadaptada al arbitraje comercial internacional. 


\section{Las modificaciones más trascendentes}

\subsection{El arbitraje como contrato}

El artículo 1649 del CCyC establece una definición del arbitraje como un contrato en donde las partes deciden someter a la decisión de uno o más árbitros todas o algunas de las controversias que hayan surgido o puedan surgir entre ellas respecto de una determinada relación jurídica, contractual o no contractual, de derecho privado en la que no se encuentre comprometido el orden público.

La definición es prácticamente idéntica al concepto de acuerdo arbitral del artículo II. 1 . de la Convención de New York sobre Reconocimiento y Ejecución de Sentencias Arbitrales Extranjeras ${ }^{13,14}$ y de la Opción II del artículo 7.1. de la Ley Modelo sobre Arbitraje Comercial Internacional, adoptada por la Comisión de las Naciones Unidas sobre el derecho mercantil internacional, el 21 de junio de $1985^{15,16}$. Solo agrega la caracterización del arbitraje como un contrato.

Uno de los puntos complejos en la materia lo constituye el determinar si los árbitros ejercen o no jurisdicción. El tema ha tenido abundante tratamiento tanto en la doctrina como en la jurisprudencia.

13. Ratificada por Argentina conforme a la Ley 23.619 del 28 de septiembre de 1988, promulgada por el Poder Ejecutivo a través del decreto 1524/88 de fecha 21 de octubre de 1988. El instrumento de ratificación fue depositado en la Naciones Unidas el 14 de Marzo de 1989 y actualmente ha sido ratificada por más de 140 países.

14. "Cada uno de los Estados Contratantes reconocerá el acuerdo por escrito conforme al cual las partes se obliguen a someter a arbitraje todas las diferencias o ciertas diferencias que hayan surgido o puedan surgir entre ellas respecto a una determinada relación jurídica, contractual o no contractual, concerniente a un asunto que pueda ser resuelto por arbitraje". (Art. II.1).

15. "El acuerdo de arbitraje es un acuerdo por el que las partes deciden someter a arbitraje todas las controversias o ciertas controversias que hayan surgido o puedan surgir entre ellas respecto de una determinada relación jurídica, contractual o no contractual. El acuerdo de arbitraje podrá adoptar la forma de una cláusula compromisoria incluida en un contrato o la forma de un acuerdo independiente".

16. La UNCITRAL (o CNUDMI en español) es un organismo intergubernamental de las Naciones Unidas que depende de la Asamblea General. Dedica sus esfuerzos a la unificación del derecho comercial internacional a través de la preparación de instrumentos legislativos y no legislativos, diseñados para asistir a la comunidad internacional en la modernización y armonización de esta materia. Está integrado por 36 Estados de todos los continentes con distintos niveles de desarrollo y sistemas jurídicos. La Ley Modelo de 1985 contiene una completa y autónoma disciplina del instituto; trata ampliamente los distintos temas que involucran al arbitraje comercial internacional desde el nacimiento del convenio arbitral hasta su reconocimiento y ejemplo. Promueve la uniformidad del derecho procesal arbitral y la armonización y el perfeccionamiento de las leyes nacionales que suelen ser inadecuadas para el arbitraje comercial internacional, y refleja el consenso mundial sobre los principios y aspectos más importantes de la práctica del arbitraje comercial internacional. Para mayor información ver el trabajo de A. PIAGgI, La vinculación entre UNCITRAL y el Arbitraje Comercial Internacional: Una relación exitosa, Ed-200, 575. 
La pregunta que el lector debe hacerse es: ¿Cuál es el origen de la función de los árbitros?, ¿ejercen los árbitros jurisdicción?, ¿tiene el árbitro imperium para imponer forzadamente su decisión a las partes?

Lo cierto es que la naturaleza jurisdiccional del arbitraje está reconocida por la Corte Suprema argentina desde el siglo XIX ${ }^{17}$, y ha sido ratificada en los casos que ha dirimido conflictos de competencia entre la justicia judicial y la arbitral ${ }^{18}$.

Este artículo reedita una antigua polémica "teórica" que entendemos se encuentra largamente superada. Algunos autores consideran al arbitraje como un contrato ${ }^{19}$, pues consideran a dicho instituto como un contrato, mientras que la doctrina argentina mayoritaria considera que el instituto -si bien nacido mediante una convención de partes- resulta esencialmente jurisdiccional, por lo que el laudo adquiere caracteres propios de una sentencia judicial ${ }^{20}$. Importante doctrina extranjera coincide con esta última postura $^{21}$.

Compartimos el criterio de FALCón en el sentido que el CCyC realiza una regulación tibia sobre el ámbito nacional e internacional del arbitraje y

17. CSN, 1880, B. DE LAS CARreras, Fallos 22:371, 376, citado por A. BiANCHI, "El Estado Nacional ante el arbitraje", LL 13.4.05.

18. CSN, 1-11-88, "S.A. La Nación y otra c/ S.A. La Razón Editorial E.F.I.C. y A.", Fallos 311:2223; ídem, 10-1188, "Nidera Argentina S.A. c/ Elena G. Rodríguez Álvarez de Canale", Fallos 311:2300, etc.

19. Rocco consideraba que el arbitraje era una transacción anticipada remitida a terceros de confianza (A. RocCo, La sentencia civil, trad. de Mariano Ovejero, España moderna, Madrid, s/f, pp. 73 a 75. Otros autores nacionales que sostienen la tesis contractualista son D. LASCANO, Jurisdicción y competencia, Buenos Aires, 1941, p. 153; R. J. Podetti, Código de Procedimientos en materia civil y comercial de Mendoza, Buenos Aires, 1936, III, p. 271; C. ZAVAla RodríGueZ, Código de Comercio y leyes complementarias comentados y concordados, Depalma, Buenos Aires, 1959, I, p. 560; cit. Por E. FAlCone, Tratado de Derecho Procesal Civil y Comercial, Tomo X, El Derecho Procesal en el Código Civil y Comercial de la Nación, Eubinzal-Culzoni Editores, 2014, p. 499.

20. A. Morello; G. Passi Lanza; L. Sosa, y R. Berizonce, Códigos Procesales en lo Civil y Comercial de la Provincia de Buenos Aires y de la Nación. Comentados y anotados, 1979, t. IX, p. 490; E. Fenochietto y R. ARAzI, Código Procesal Civil y Comercial de la Nación, Buenos Aires, 1993, III, p. 503. Otros autores que se pueden citar en el mismo sentido: M. ОTTOLENGHI, Conceptos fundamentales para una construcción del instituto arbitral, en Revista de Derecho Procesal, 1943, $1^{\circ}$ parte, pp. 184 y ss.; C. Ayarragaray, Naturaleza del proceso arbitral; R. FERNÁnDEZ, Derecho Procesal Civil, 1955, I, 618 y en sentido similar: Código de Comercio, I, VOL. 2, PS. 1229 Y 1230; R. FERnÁNDEZ y L. GóMEZ, R. Osvaldo, Tratado teórico-práctico de Derecho Comercial, Lexis Nexis, Buenos Aires, 2006, t. I, párr.. 49, a, etc.

21. Ver sobre el particular: A. REDFERN y M. HUNTER, Law and Practice of International Commercial Arbitration, Thompson, Londres, 2004; y T. CARbonneaU, Cases and Materials on the Law and Practice of Arbitration, Juris Publishing, New York, 2000, pp. 2 y ss. 
que erróneamente considera al arbitraje como un contrato. Coincidimos con el citado autor que el arbitraje no tiene como objeto de sí mismo ninguna relación jurídica patrimonial, sino que su objeto es la creación de un tribunal para dirimir un conflicto jurídico ${ }^{22}$.

La Corte Suprema de Justicia de Argentina ha reconocido el origen jurisdiccional del arbitraje en muchísimas oportunidades ${ }^{23}$.

\subsection{La forma. El acuerdo arbitral}

La determinación de los requisitos formales aplicables al acuerdo arbitral corresponde a la legislación nacional sobre arbitraje.

El acuerdo arbitral es un acto jurídico que exterioriza la voluntad de las partes de someterse a arbitraje y, debido a la naturaleza contractual del arbitraje, es esa voluntad la que permite que se inicie y tenga lugar un procedimiento arbitral, renunciando por ende a la jurisdicción ordinaria como forma de resolver las disputas. Fue reiteradamente decidido por la Corte Suprema que la sujeción al arbitraje importa la renuncia a la Jurisdicción que ejercen los órganos del Poder Judicial ${ }^{24}$.

La competencia creada convencionalmente no puede ser disputada por los jueces estatales ya que la exclusividad de aquél es un aspecto importante en su setatus y sirve para enfatizar su carácter independiente ${ }^{25}$.

Ahora bien: El CCyC establece la necesidad de la existencia de un acuerdo arbitral por escrito, ya sea que esté contenida en una cláusula compromisoria incluida en un contrato o en un acuerdo independiente o en un estatuto o reglamento ${ }^{26}$.

22. E. Falcon, Tratado de Derecho Procesal Civil y Comercial, Tomo X, El Derecho Procesal en el Código Civil y Comercial de la Nación, Rubinzal-Culzoni Editores, 2014, pp. 503 y ss.

23. Con cita: CSJN, "Bruce c/DE LAS CARRERAs", Fallos: 22:371 (año 1880); 1-11-88, "S.A. La Nación y otra c/S.A. La Razón Editorial EFICyA”, Fallos: 311:2223; 10-11-88, “Nidera Argentina S.A. c/E. G. RoDRíGuEz ÁLVAREZ DE CANALE", Fallos: 311:23.

24. CSJN, Fallos 107:126; 302:1280 y 305:1365.

25. Chillón Medina-Merino Merchan, "Tratado de Arbitraje Privado Interno e Internacional", p. 296, Ed. Civitas-Madrid 1991.

26. Art. 1650. Forma. El acuerdo de arbitraje debe ser escrito y puede constar en una cláusula compromisoria incluida en un contrato o en un acuerdo independiente o en un estatuto o reglamento. La referencia hecha en un contrato a un documento que contiene una cláusula compromisoria constituye contrato de arbitraje siempre que el contrato conste por escrito y la referencia implique que esa cláusula forma parte del contrato. 
Adviértase que la norma en análisis requiere:

a) Que el acuerdo arbitral sea escrito.

b) Que esté contenido en una cláusula compromisoria incluida en un contrato o en un acuerdo independiente.

c) La referencia hecha en un contrato a un documento que contiene una cláusula compromisoria constituye contrato de arbitraje siempre que el contrato conste por escrito y la referencia implique que esa cláusula forma parte del contrato.

En primer lugar, la pregunta que surge de la lectura de este artículo es si el requisito material del acuerdo arbitral escrito es ad substantiam o ad probationem, o ambas, de tal manera que determina la existencia misma del acuerdo y asimismo es un elemento de convicción o prueba. De esta manera se pretende evitar litigios sobre la existencia misma del acuerdo, por lo que, de no cumplirse con el requisito, no sería prorrogable la jurisdicción por inexistencia de acuerdo arbitral, y el eventual laudo que bajo dichas circunstancias se dictare no sería ejecutable.

En materia contractual la regla general es que los contratos se perfeccionan con el mero consentimiento; basta entonces la voluntad de las partes para que surtan efecto. Para que la voluntad adquiera relevancia jurídica debe salir de la esfera interna del sujeto emisor, esto es, debe existir un hecho exterior por el que se manifieste. La exteriorización puede darse de manera expresa o tácita ${ }^{27}$.

Por otro lado, la necesidad de que el acuerdo arbitral conste por escrito ha perdido cierta actualidad ${ }^{28}$. La práctica indica que sin existir un acuerdo escrito resulta posible probar la intención de la partes. Entre la casuística posible podemos mencionar los siguientes ${ }^{29}$ :

27. A. SAldARRIAGA, "El requisito de forma escrita del artículo II.2 de la Convención de Nueva York y la doctrina del grupo de sociedades. ¿Está de más en el arbitraje internacional?", en El Arbitraje Comercial Internacional Estudio de la Convención de Nueva York con motivo de su 50ªniversario, Abeledo Perrot, 2008, p. 263.

28. Igualmente, hay legislaciones nacionales, como el artículo 29 de la Ley de El Salvador que exige la forma escrita.

29. Cfr. F. GONZÁLEZ dE Cossío, "Validez del acuerdo arbitral bajo la Convención de Nueva York: un ejercicio conflictual", en El Arbitraje Comercial Internacional - Estudio de la Convención de Nueva York con motivo de su $50^{\circ}$ aniversario, Abeledo Perrot, 2008, p. 429. 
a) Los acuerdos celebrados por medios electrónicos;

b) Los intercambios de cartas y telegramas;

c) El cumplimiento del contrato que no fuera firmado por una de las partes o cuando la operación fue documentada en varios contratos que contienen sendos acuerdos arbitrales firmados por las partes; pero uno de ellos no se firma;

d) El certificado de embarque emitido por un porteador que no es firmado por el cargador y que contiene una cláusula arbitral;

e) El contrato que contiene un acuerdo arbitral y es enviado a una parte que no lo acepta expresamente ante la otra, pero se refiere por escrito a dicho contrato en correspondencia subsiguiente;

f) Cuando el demandante inicia un arbitraje en contra de una identidad que no es la parte que originalmente firmó el acuerdo arbitral o basándose en teorías de derecho local como son alter ego, inoponibilidad de la persona jurídica o la "teoría de grupos".

Muchos otros ejemplos podrían proponerse al lector.

Afortunadamente, no aclara el artículo 1650 que el acuerdo deba ser firmado por las partes. El requisito de forma escrita se exige en relación al contenido del acuerdo arbitral y del contrato al que hace referencia. No así de la manifestación del consentimiento de las partes.

En consecuencia, bastaría con que una de las partes presentase un contrato que contenga una cláusula arbitral o un intercambio de cartas o documentos que, si bien no fue firmado por la otra parte, surja el consentimiento de aquel a través de su conducta, por ejemplo, de su participación en la ejecución del contrato ${ }^{30}$.

Por ello, entendemos que el acuerdo arbitral puede surgir de un intercambio de cartas, telegramas u otros medios de telecomunicaciones ${ }^{31}$ que de-

30. Tal lo dispuesto en el artículo $6^{\circ}$ de la Ley de Mediación yArbitraje de Ecuador.

31. Entendemos que la exteriorización del acuerdo arbitral por escrito puede ser cumplida por medios electrónicos 
jen constancia del acuerdo, o en un intercambio de escritos de demanda o contestación en los que la existencia de un acuerdo sea afirmada por una parte sin ser negada por la otra, o bien se considere aceptado el acuerdo arbitral por las partes en forma tácita por silencio o actos de ejecución del contrato o acuerdo perfeccionado.

Por lo expuesto, podemos concluir que corresponde una interpretación amplia del artículo, por lo que es suficiente que exista constancia documental de algún tipo que haga evidente la voluntad de pactar un acuerdo arbitral aunque no exista la firma de alguna o de ambas partes en un documento, ya sea el contrato en cuestión o un apéndice de éste. Incluso sería obligatorio el acuerdo arbitral entre no signatarios conforme la doctrina del grupo de sociedades $^{32}$. Dicha interpretación abierta sería acorde con las decisiones de las cortes nacionales de otros países ${ }^{33}$. Entendemos que el CCyC elimina la formalidad ad solemnitatem exigida al convenio arbitral, por lo que ahora bastaría probar el consentimiento de las partes.

En segundo lugar, la redacción de la norma no es novedosa. Ahora bien, la constancia escrita no es tan solemne, porque bastará que el acuerdo esté consignado en un documento separado o apéndice que indique la referencia al contrato del que forma parte. Incluye, por ende, la incorporación por referencia, es decir, aquel instrumento jurídico en virtud del cual un documento se convierte en parte de otro simplemente por la mera referencia de aquél ${ }^{34}$.

de comunicación, siempre que la información consignada en ella sea accesible para su ulterior consulta, entendiéndose por "comunicación electrónica" a cualquier comunicación que las partes hagan por medio de mensajes de datos, expresión que debe ser interpretada como comprensiva de información generada, enviada, recibida o archivada por medios electrónicos, magnéticos, ópticos o similares, como pudieran ser, entre otros sin limitarse, el intercambio electrónico de datos, el correo electrónico, el telegrama, el télex o el telefax (tal como señala el artículo 7.4. de la versión del año 2006 de la Ley Modelo de la CNUDMI).

32. Ver artículo $14^{\circ}$ de la Ley de Arbitraje Peruana: "El convenio arbitral se extiende a aquellos cuyo consentimiento de someterse a arbitraje, según la buena fe, se determina por su participación activa y de manera determinante en la negociación, celebración, ejecución o terminación del contrato que comprende el convenio arbitral o al que el convenio esté relacionado. Se extiende también a quienes pretendan derivar derechos o beneficios del contrato, según sus términos."

33. Sobre este tema sugerimos la lectura de los artículos de SALDARRIAGA, ob., cit.18; y C. SUÁREZ ANZORENA, La Doctrina de los grupos de sociedades y los alcances del acuerdo arbitral, IX Congreso Argentino de Derecho Societario, V Congreso Iberoamericano de Derecho Societario y de la Empresa (San Miguel de Tucumán, 2004), pp. 539-548.

34. La figura de "la incorporación por referencia" ha sido incorporada a otros instrumentos internacionales, como La Ley Modelo de la CNUDMI en materia de Contratación Electrónica, citado por C. VON WOBESER, La incorporación por referencia, en El Arbitraje Comercial Internacional - Estudio de la Convención de Nueva York con motivo de su 50ªniversario, Abeledo Perrot, 2008, p. 259, cita nº 17. 
Pero el tema no termina ahí. La legislación argentina parece contemplar los dos tipos de incorporaciones por referencia, la general a un contrato o documento como tal (en un acuerdo independiente o en un estatuto o reglamento) o especial, es decir a una parte del documento (la referencia hecha en un contrato a un documento que contiene una cláusula compromisoria que constituye contrato de arbitraje siempre que el contrato conste por escrito y la referencia implique que esa cláusula forma parte del contrato).

El CCyC va más allá de lo dispuesto por el artículo II párrafo $2^{\circ}$ de la Convención de Nueva York y del artículo $1^{\circ}$ de la Convención Interamericana sobre Arbitraje Comercial Internacional (Convención de Panamá), pues en ambos textos internacionales -ratificados por la República Argentina- no se contempla la incorporación por referencia.

Lo expuesto plantea el siguiente problema: pudiera no brindarse el reconocimiento y ejecución de un laudo dictado con sede en la Argentina si el Estado en el que se intenta la ejecución forma parte de la Convención de Nueva York y aplica la interpretación restrictiva del artículo II.2 que no contempla la incorporación por referencia como uno de los supuestos para considerar a un acuerdo arbitral como otorgado por escrito.

En tercer lugar, la redacción del artículo permite afirmar que se deja de lado el concepto de acuerdo arbitral representado en varios actos: una cláusula compromisoria y un posterior compromiso arbitral ${ }^{35}$. Ambas se encuentran incluidas en el concepto de acuerdo arbitral y solo se diferencian respecto a su inclusión o no en el contrato celebrado entre las partes, y, si bien el artículo no lo dispone expresamente, respecto del momento en que las partes convienen en someter un determinado conflicto a arbitraje ${ }^{36}$.

35. Uno de los aspectos más criticados de la legislación procesal argentina es que la cláusula compromisoria no es suficiente por sí, pues es exigencia legal que las partes suscriban el compromiso arbitral, el que debe formalizarse una vez que ha surgido el conflicto, por escritura pública o instrumento privado o por acta extendida ante el juez de la causa o ante aquel a quien hubiese correspondido su conocimiento (Art. 739 Código Procesal). La pregunta que surge evidente es si luego de entrar en vigencia el CCCN continúa la obligación de las partes de suscribir el compromiso arbitral.

36. Se utilizará la expresión "acuerdo arbitral", tanto para referirnos a la "cláusula compromisoria", es decir, el acuerdo genérico ex ante por el que dos o más partes someten a arbitraje un determinado tipo de controversias futuras, como para referirnos al "compromiso arbitral", es decir, el acto mediante el cual las partes someten a arbitraje una determinada controversia existente, haya o no una cláusula compromisoria previa. Igualmente, debe notarse que la problemática que trata esta contribución es difícil de concebir en el último caso, por cuanto las partes o los jueces definen los alcances subjetivos del procedimiento arbitral (C. SuÁREZ ANZORENA, "Algunas notas sobre los grupos de sociedades y los alcances del acuerdo arbitral según la práctica internacional", Revista Internacional de Arbitraje, Enero-Junio 2005). 
La cláusula compromisoria constituye un medio por el cual las partes -en un ejercicio de autonomía admitido por el ordenamiento jurídicoresuelven atribuir jurisdicción a un árbitro o a un tribunal de arbitradores para resolver sus controversias, configurando un acuerdo contractual que se debe acatar ${ }^{37}$.

Caivano la define como "el convenio por el cual las partes deciden someter algunos asuntos a arbitraje, sustrayéndolos al conocimiento de los jueces ordinarios. Las partes renuncian a que sean decididos por los tribunales de justicia, asignándoselos a particulares, a quienes invisten, como consecuencia de ello, de funciones y facultades jurisdiccionales. Pero las divergencias a las que se refiere son todavía, al momento de suscribir la cláusula, meramente eventuales. Ni siquiera se sabe si llegarán a producirse. Es un convenio previo al conflicto mismo, cuyos efectos dependen de la legislación que le sirva de base" 38 .

Coincidimos con PARodi en que, pese a que mediante el compromiso arbitral existe la posibilidad de elaborar un acuerdo de arbitraje detallado y adecuado a las especiales características y circunstancias de la disputa concreta que lo origina, la experiencia demuestra la conveniencia de incluir la cláusula arbitral en el mismo contrato, ya que, en la mayoría de los casos, cuando el conflicto ha surgido, las partes difícilmente se pondrán de acuerdo en algo, inclusive en la forma de resolverlo ${ }^{39}$.

Finalmente, el artículo $1658^{40}$ establece ciertas cláusulas facultativas del acuerdo arbitral, tales como la referida a la sede arbitral, el idioma, el procedimiento arbitral, el plazo del mismo, la confidencialidad y lo referido

37. C. E. Fenochietto, "Código Procesal Civil y Comercial de la Nación”, tomo 3, editorial Astrea, 1999, comentario al Art. 739, p. 716.

38. R. J. CaIvano, Arbitraje, $2^{\circ}$ edición, 2000, Ad- Hoc, p. 115.

39. G. PARODI, Contrato de Arbitraje, Código Civil y Comercial de la Nación Comentado.

40. Art. 1658.- Cláusulas facultativas. Se puede convenir:
a) la sede del arbitraje;
b) el idioma en que se ha de desarrollar el procedimiento;
c) el procedimiento al que se han de ajustar los árbitros en sus actuaciones. A falta de acuerdo, el tribu- nal arbitral puede dirigir el arbitraje del modo que considere apropiado;
d) el plazo en que los árbitros deben pronunciar el laudo. Si no se ha pactado el plazo, rige el que es- tablezca el reglamento de la entidad administradora del arbitraje, y en su defecto el que establezca el derecho de la sede;
e) la confidencialidad del arbitraje;
f) el modo en que se deben distribuir o soportar los costos del arbitraje. 
a los $\operatorname{costos}^{41}$, los cuales parecen en parte coincidir con la más moderna tendencia internacional en la materia ${ }^{42}$.

\subsection{Materias excluidas}

El artículo 1651 excluye ciertas controversias de ser sometidas a arbitraje: a) las que se refieren al estado civil o la capacidad de las personas; b) las cuestiones de familia; c) las vinculadas a derechos de usuarios y consumidores; d) los contratos por adhesión cualquiera sea su objeto; e) las derivadas de relaciones laborales. Las disposiciones de este Código relativas al contrato de arbitraje no son aplicables a las controversias en que sean parte los Estados nacional o local ${ }^{43}$.

De la lectura del artículo se deduce que el resto de las cuestiones pueden ser sometidas a arbitraje.

En concreto, nos parece evidente que se puede someter a arbitraje todo aquello que puede ser materia de transacción ${ }^{44}$; y el Código Civil au-

41. Sobre este punto sugerimos la interpretación que hace el artículo $71^{\circ}$ de la Ley Peruana de Arbitraje.- Honorarios del tribunal arbitral Los honorarios del tribunal arbitral y del secretario, en su caso, serán establecidos de manera razonable, teniendo en cuenta el monto en disputa, la dimensión y la complejidad del caso, el tiempo dedicado por los árbitros, el desarrollo de las actuaciones arbitrales, así como los usos y costumbres arbitrales y cualesquiera otras circunstancias pertinentes del caso.

42. Nos referimos en particular a las directivas de la International Bar Association (IBA) para la Redacción de Cláusulas de Arbitraje Internacional, que fueron adoptadas por la Resolución del Consejo de la IBA el 7 de Octubre de 2010.

43. La Ley de Mediación, Conciliación y Arbitraje de El Salvador establece ciertas materias excluidas en sus artículos 23 y 24. Art. 23.- No podrán ser objeto de arbitraje:

a) Los asuntos contrarios al orden público o directamente concernientes a las atribuciones o funciones de imperio del Estado o de personas de derecho público;

b) Las causas penales, excepto en lo relativo a la responsabilidad civil proveniente del delito;

c) Los alimentos futuros;

d) Las controversias relativas a bienes o derechos de incapaces, sin previa autorización judicial;

e) Aquellos conflictos relacionados con el estado familiar de las personas, excepto en lo relativo al régimen patrimonial atinente con éste; $y$

f) Las cuestiones sobre las cuales haya recaído sentencia judicial firme.

Expresa Exclusión de la Materia Laboral

Art. 24.- Las controversias de índole laboral no quedan sujetas a lo dispuesto por la presente ley.

Lo mismo ocurre con el artículo $6^{\circ}$ de la ley 1770 de Bolivia: Articulo 6.- (Materias excluidas de arbitraje) I. No podrán ser objeto de arbitraje: 1. Las cuestiones sobre las que haya recaído resolución judicial firme y definitiva, salvo los aspectos derivados de su ejecución. 2. Las cuestiones que versen sobre el estado civil y la capacidad de las personas. 3. Las cuestiones referidas a bienes o derechos de incapaces, sin previa autorización judicial. 4. Las cuestiones concernientes a las funciones del Estado como persona de derecho público. II. Las cuestiones laborales quedan expresamente excluidas del campo de aplicación de la presente ley, por estar sometidas a las disposiciones legales que les son propias.

44. Tal como ocurre en ciertas leyes nacionales, como el artículo $1^{\circ}$ de la Ley de Mediación y Arbitraje de Ecua- 
toriza la transacción sobre todo aquello que puede ser materia de convención privada, o sea que solo excluye aquellas materias indisponibles para las partes (estado de familia, validez o nulidad del matrimonio, derecho a alimentos, herencia futura) y las que se refieren a hechos o cosas que no pueden ser objeto de actos jurídicos.

Es por ello que compartimos los argumentos de AguiLAR en el sentido que en el Código Procesal argentino se restringen las materias arbitrables, y por ende la capacidad de las partes para acordar el arbitraje, a las cuestiones que pueden ser objeto de transacción ${ }^{45}$. Menciona este autor que, el ámbito del arbitraje que ha incorporado otras materias que hoy son arbitrables tales como, entre otras, las controversias entre socios en el seno de las sociedades anónimas ${ }^{46}$, en temas de familia si se trata de controversias de naturaleza puramente patrimonial.

Hubiéramos preferido una redacción similar a la del artículo $2^{\circ}$ del Decreto Legislativo $\mathrm{N}^{\circ} 1071$ de la Ley Nacional del Perú donde pueden someterse a arbitraje las controversias sobre materias de libre disposición conforme a derecho, así como aquellas que la ley o los tratados o acuerdos internacionales autoricen ${ }^{47}$.

Adviértase que el artículo 1651 excluye las cuestiones de familia sin distinción. No compartimos ese criterio ${ }^{48}$.

dor; y la Ley de Mediación, Conciliación y Arbitraje de El Salvador que dispone en su Art. 22.- Podrán someterse a arbitraje las controversias que surjan o puedan surgir entre personas naturales o jurídicas capaces, sobre materias civiles o comerciales respecto de las cuales tengan libre disposición.

45. Art. 737 Código Procesal: No podrán comprometerse en árbitros bajo pena de nulidad, las cuestiones que no pueden ser objeto de transacción.

46. Es oportuno aclarar que la Resolución General No 4/2001 dictada por la Inspección General de Justicia fue dictada en virtud de una recomendación de la Comisión Consultiva sobre Arbitraje que expuso la conveniencia de incluir una cláusula arbitral para la composición de diferencias, conflictos o controversias entre socios, derivadas de contratos o estatutos sociales (párrafo $2^{\circ}$ de la Resolución). Asimismo, la resolución indica que las cláusulas arbitrales apuntan a brindar soluciones frente a hipótesis de conflictos derivados del contrato social o de su interpretación (párrafo $3^{\circ}$ )...siendo dicha cláusula admisible bajo los alcances que el principio de la autonomía de la voluntad de los contratantes reconoce en materia societaria. La Inspección General de Justicia admite la inclusión de cláusulas arbitrales en los contratos de sociedades de responsabilidad limitada, en los estatutos de sociedades por acciones sometidas a su contralor y en lo contratos de colaboración empresaria regulados por la Ley 19.550 (Art. $1^{\circ}$ de la Resolución). Incluso dicha resolución presenta dos modelos de cláusulas arbitrales en los anexos A y $\mathrm{B}$.

47. Ver artículo $3^{\circ}$ de la Ley 1770 de Bolivia: Pueden someterse a arbitraje las controversias surgidas o que puedan surgir de relaciones jurídicas contractuales o extracontractuales de las partes, mediante el ejercicio de su libre arbitrio sobre derechos disponibles y que no afecten al orden público, antes, en el transcurso o después de intentado un proceso judicial, cualquiera fuere el estado de éste, extinguiéndolo o evitando el que podría promoverse.

48. La Comisión Bicameral del Congreso eliminó del texto original la posibilidad de someter a arbitraje las cuestiones patrimoniales de familia. 
Tampoco compartimos la exclusión de los contratos de adhesión, cualquiera sea su objeto. ¿Significa esto que se puede excluir como materia arbitral a los contratos llamados de comercialización, en particular, agencia (artículos 1479 a 1501), concesión-distribución (artículos 1502 a 1511) y franquicia (artículos 1512 a 1524), por haber sido firmados con cláusulas predispuestas escritas? El legislador pretende de esta manera proteger a la parte contractual más débil pero lo hace con un criterio que aleja a la legislación argentina de las más modernas tendencias en materia arbitral, incluso con el artículo 4.2. del Acuerdo del MERCOSUR, además de que nos parece un contrasentido que el legislador permita el sometimiento a arbitraje por referencia y no por adhesión ${ }^{49}$.

Desde nuestro punto de vista, hubiera sido más apropiada una redacción más moderna, donde convenios referidos a relaciones jurídicas contenidas en cláusulas generales de contratación o contratos por adhesión serán exigibles sólo si dichos convenios han sido conocidos, o han podido ser conocidos por quien no los redactó, usando una diligencia ordinaria ${ }^{50}$.

Se excluyen asimismo las cuestiones vinculadas a los consumidores y a las relaciones laborales, por contar con disposiciones específicas en la materia.

Finalmente, las disposiciones del CCyC relativas al contrato de arbitraje no son aplicables a las controversias en que sean parte los Estados nacional

49. Ver sobre el particular la Ley de Conciliación, Mediación y Arbitraje de El Salvador: Art. 26.- Los convenios arbitrales referidos a relaciones jurídicas contenidas en cláusulas generales de contratación, contratos normalizados o contratos por adhesión, serán plenamente válidos entre las partes en tanto dichos convenios hayan sido conocidos o debían conocerse por la contraparte y su manifestación de voluntad de someterse al arbitraje se hiciere en forma expresa e independiente.

Se presume, sin admitir prueba en contrario, que el convenio arbitral debía conocerse, si se cumple con alguno de los siguientes supuestos:

a) Si las condiciones generales que incluyen el convenio arbitral se hallan insertas en el cuerpo del contrato principal y este último es por escrito y está firmado por ambas partes;

b) Si las condiciones generales, a pesar de no estar reproducidas en el cuerpo del contrato principal, constan en el reverso del documento y se hace referencia al convenio arbitral en el cuerpo del contrato principal y éste es por escrito y firmado por la otra parte;

c) Si el convenio arbitral se encuentra incluido en condiciones generales separadas del documento principal, pero se hace referencia en el cuerpo del contrato principal a la existencia del arbitraje y éste es por escrito y firmado por la otra parte; $y$, la negativa del consumidor o usuario a someterse a un convenio arbitral no podrá impedir por sí misma la celebración del contrato principal.

50. Ver artículo $15^{\circ}$ de la Ley Peruana de Arbitraje 
o local ${ }^{51}$. Entendemos que esto es un error. Cuando la Constitución argentina estableció en su artículo 116 la jurisdicción de la Corte para los juicios en que la Nación es parte, no ha excluido la jurisdicción arbitral ${ }^{52}$. Además, es doctrina del máximo tribunal argentino que el principio general del artículo 116 de la Constitución Argentina no impide al Estado convenir una cláusula arbitral siempre que el Estado esté autorizado por ley para someter a árbitros las cuestiones que se plantean con motivo de los contratos que celebra; debiendo el Estado estar actuando como persona jurídica ${ }^{53}$ salvo aquellas cuestiones que hacen al orden público o en las que estén en juego los poderes públicos o los atributos de la soberanía ${ }^{54}$.

Esta cuestión tiene directa relación con la limitación del arbitraje a relaciones de derecho privado que hace el artículo 1549, excluyendo las materias reguladas por normas de orden público. Entendemos que el legislador ha cometido un

51. Entendemos más acorde con las tendencias internacionales la redacción del artículo $4^{\circ}$ de la Ley Nacional de Perú. Sin embargo, el artículo $4^{\circ}$ de la Ley de Mediación y Arbitraje de Ecuador establece lo siguiente: Para que las diferentes entidades que conforman el sector público puedan someterse al arbitraje, además de cumplir con los requisitos que establece esta Ley, tendrán que cumplir los siguientes requisitos adicionales: Pactar un convenio arbitral, con anterioridad al surgimiento de la controversia; en caso de que se quisiera firmar el convenio una vez surgida la controversia, deberá consultarse al Procurador General del Estado, dictamen que será de obligatorio cumplimiento; la relación jurídica al cual se refiere el convenio deberá ser de carácter contractual; en el convenio arbitral deberá incluirse la forma de selección de los árbitros; y, el convenio arbitral, por medio del cual la Institución del sector público renuncia la jurisdicción ordinaria, deberá ser firmado por la persona autorizada para contratar a nombre de dicha Institución. El incumplimiento de los requisitos señalados acarreará la nulidad del convenio arbitral.

52. Artículo 116: Corresponde a la Corte Suprema y a los tribunales inferiores de la Nación, el conocimiento y decisión de todas las causas que versen sobre puntos regidos por la Constitución, y por las leyes de la Nación, con la reserva hecha en el inc. 12 del artículo 75: y por los tratados con las naciones extranjeras, de las causas de almirantazgo y jurisdicción marítima, de los asuntos en que la Nación sea parte, de las causas que se susciten entre dos o más provincias, y entre una provincia o sus vecinos, contra un Estado o ciudadano extranjero.

53. Ver Ley de Conciliación, Mediación y Arbitraje de El Salvador: Art. 25.- Podrán someterse a arbitraje las controversias en las que el Estado y las personas jurídicas de derecho público son partes interesadas, siempre que versen sobre derechos disponibles y deriven de una relación jurídica patrimonial de derecho privado o de naturaleza contractual.

En las controversias derivadas de los contratos que el Estado Salvadoreño o las personas de derecho público celebren con nacionales o con extranjeros domiciliados, se estará a lo dispuesto en leyes especiales o en tratados o convenios internacionales y, en su defecto, a lo establecido por esta ley. Podrán conocer del arbitraje para este tipo de controversias los Centros establecidos por la presente Ley. Las empresas de derecho privado con capital estatal o las de economía mixta pueden acordar libremente y sin requisito de previa autorización que las controversias derivadas de los contratos que celebren con nacionales o extranjeros domiciliados o que se refiere a sus bienes propios, sean sometidas a Arbitraje.

Ver asimismo el artículo $4^{\circ}$ de la Ley 1770 de Bolivia.- (Capacidad estatal) I. Podrán someterse a arbitraje, lascontroversias en las que el Estado y las personas jurídicas de Derecho Público son partes interesadas, siempre que versen sobre derechos disponibles y deriven de una relación jurídica patrimonial de derecho privado o de naturaleza contractual. II. Conforme a lo establecido en el parágrafo anterior, el Estado y las personas jurídicas de Derecho Público tienen plena capacidad para someter sus controversias a arbitraje nacional o internacional, dentro o fuera del territorio nacional, sin necesidad de autorización previa. (ART. 76 LEY 1770).

54. Fallos: 90:97; 104:323; 110:35; 143:357; 146:373; 167:192; CSJN del 16/08/1937, Cía. Italo Argentina de Electricidad c/ La Nación, Fallos 178:29, citados por J.C. RIVERA, ob. cit. 45. 
error inexcusable, dado que el hecho de que una materia sea regulada por normas de orden público no implica que no pueda ser sometida a arbitraje, sino la posibilidad que las partes pueden disponer de los derechos en cuestión.

\subsection{El arbitraje de equidad y de derecho}

El artículo 1652 contempla el arbitraje de equidad o ex aequo et bono y el arbitraje de derecho o iuris, siendo el arbitraje de derecho si el acuerdo arbitral no lo estipula expresamente ${ }^{55}$.

Este artículo dispone exactamente lo contrario que el artículo 766 del Código Procesal donde se establece que "si nada se hubiese estipulado en el compromiso acerca de si el arbitraje es de derecho o de amigables componedores, o si se hubiese autorizado a los árbitros a decidir la controversia según equidad, se entenderá que es de amigables componedores". Sin perjuicio de la contradicción, coincidimos con el nuevo criterio, acorde con las más modernas reglas en la materia ${ }^{56}$. Recoge la tendencia internacional de que los arbitrajes sean de derecho, salvo pacto en contrario de las partes ${ }^{57}$.

Coincidimos con destacadas autoras nacionales que, al ser de derecho el arbitraje, entendemos que el laudo debe ajustarse a las normas estrictas del derecho, y deben ser motivados ${ }^{58}$.

\subsection{La autonomía del acuerdo arbitral. La competencia de los árbitros}

Por medio de los artículos $1653^{59}$ y $1654^{60}$ el CCyC consagra dos de los principios más significativos del arbitraje: el de autonomía (separabilidad) de la cláusula arbitral y la competencia de los árbitros para decidir disputas sobre su

55. Art. 1652.- Clases de arbitraje. Pueden someterse a la decisión de arbitradores o amigables componedores, las cuestiones que pueden ser objeto del juicio de árbitros. Si nada se estipula en el convenio arbitral acerca de si el arbitraje es de derecho o de amigables componedores, o si no se autoriza expresamente a los árbitros a decidir la controversia según equidad, se debe entender que es de derecho.

56. Artículo 28.3. Ley Modelo CNUDMI y artículo $9^{\circ}$ Acuerdo sobre Arbitraje del MERCOSUR. Ver asimismo el artículo $41^{\circ}$ de la Ley Peruana de Arbitraje; artículo 11 de la Ley 1770 de Bolivia; y artículo 30 de la Ley de Arbitraje de El Salvador.

57. En contra, por ejemplo, el artículo $3^{\circ}$ de la Ley de Mediación y Arbitraje de Ecuador.

58. S. Feldstein de CÁrdenas - H. Leonardi De Herbón: "El arbitraje", Abeledo Perrot, Bs. As., 1998, p. 13.

59. Art. 1653. Autonomía. El contrato de arbitraje es independiente del contrato con el que se relaciona. La ineficacia de éste no obsta a la validez del contrato de arbitraje, por lo que los árbitros conservan su competencia, aun en caso de nulidad de aquél, para determinar los respectivos derechos de las partes y pronunciarse sobre sus pretensiones y alegaciones.

60. Art. 1654. Competencia. Excepto estipulación en contrario, el contrato de arbitraje otorga a los árbitros la atribución para decidir sobre su propia competencia, incluso sobre las excepciones relativas a la existencia 
propia competencia (Kompetenz-Kompetenz), lo cual permite proteger la autonomía del proceso arbitral sin la interferencia de los tribunales locales, con lo que, en cualquier caso, la validez o invalidez de la cláusula arbitral será decidida por el tribunal arbitral, lo mismo que sus alcances y las materias arbitrales $^{61}$.

En este ámbito, el principio referido de la autonomía de la cláusula compromisoria es internacionalmente admitido y como tal incorporado a la ley modelo de la CNUDMI ${ }^{62}$.

La misma Secretaría de la CNUDMI manifestó que la doctrina de Kompetenz-Kompetenz implica que el tribunal arbitral podrá decidir independientemente acerca de su propia competencia, incluso sobre toda excepción que se haya opuesto contra la existencia o a la validez del acuerdo de arbitraje, sin tener que recurrir a un tribunal arbitral. La separabilidad de la cláusula compromisoria supone que ésta debe considerarse a un acuerdo independiente de las demás condiciones del contrato ${ }^{63}$.

Esto significa lo siguiente: La autonomía del acuerdo arbitral supone que en caso de que la cláusula compromisoria se encuentre inserta en un o acuerdo general, esa cláusula es considerada como autónoma y separable del acuerdo principal. De este modo, si los árbitros resuelven que el contrato en el cual se encuentra inserta dicha cláusula es nulo, ello no implicará la nulidad del acuerdo arbitral. Lo contrario importaría necesariamente la pérdida automática de competencia de ese mismo tribunal arbitral interviniente y la consecuente imposibilidad de continuar con el procedimiento de arbitraje en curso. La doctrina Kompetenz-Kompetenz resuelve el interrogante referido a quién es competente para resolver un cuestionamiento sobre la competencia de un tribunal arbitral. Según este principio, generalmente aceptado, es el tribunal arbitral que debe resolver sobre su propia competencia ${ }^{64}$.

o a la validez del convenio arbitral o cualesquiera otras cuya estimación impida entrar en el fondo de la controversia.

61. Es oportuna la mención de FALCón sobre la legislación procesal de la Provincia de Río Negro que dispone en su artículo 739, último párrafo, lo siguiente: "La declaración de invalidez de un contrato no importará la del acuerdo arbitral, salvo que ésta fuera consecuencia inescindible de aquélla”, ob. cit. p. 509.

62. A. BoggIAno, "Derecho internacional privado", t. III, cap. XXVI, p. 303.

63. Nota explicativa de la secretaría de la CNUDMI acerca de la Ley Modelo sobre Arbitraje Comercial Internacional de 1985, en su versión enmendada en 2006, párrafo 25.

64. M. ROTHENBERG, El principio Kompetenz-Kompetenz y su aplicación a un reciente caso de arbitraje comercial internacional, LA LEY 23/11/2010 , 6 • LA LEY 2010-F , 353, AR/DOC/7704/2010. 
Así lo han reconocido los tribunales argentinos al decidir que "no altera la naturaleza de convención autónoma, que puede ser contemporánea o no al contrato principal, pero que no depende de este último en cuanto a su validez, a la ley aplicable, ni al juez dotado de jurisdicción para resolver una eventual controversia" 65 .

Es reiterada la corriente jurisprudencial nacional que entiende de carácter restrictivo la interpretación del alcance de las cláusulas compromisorias que implican una renuncia al principio general de sometimiento de los conflictos a los jueces ordinarios ${ }^{66}$.

La Cámara Nacional de Apelaciones en lo Comercial, en el fallo Enrique Welbers S.A., que dispuso "que la forma en que se instrumenta la cláusula arbitral no altera su naturaleza de convención autónoma, que puede ser contemporánea o no al contrato principal, pero que no depende de este último en cuanto a su validez, a la ley aplicable, ni al juez dotado de jurisdicción internacional para resolver una eventual controversia" ${ }^{67}$.

Del mismo modo se expidió el fuero comercial de la capital federal en in re El Diamante ${ }^{68}$. En esa línea se ha interpretado a nivel internacional esta situación, así la Convención de las Naciones Unidas sobre Compraventa Internacional de Mercaderías, conocida como Convención de Viena ${ }^{69}$, en su artículo 81.1 dispone que la resolución del contrato no afectará las estipulaciones relativas a la solución de controversias; habiéndose entendido que se refiere a las cláusulas de selección del foro, entre las que se encuentra, sin dudas, el acuerdo arbitral.

Asimismo, se ha resuelto que solo se debe controlar aquí la existencia de la antes mencionada cláusula, y corresponde al tribunal arbitral establecer su interpretación. Y es así que haciendo hincapié en que el principio de la autonomía de la cláusula compromisoria es admitido internacionalmente,

65. CNCom., Sala E, L.L. 1989-E-304.

66. Conf. C. Nac. Com., sala B, in re "Klein, Santiago E. v. Melton S.A. s/ordinario", del 29/12/2004; en igual sentido, sala E, in re "NL. S.A. v. Bull Argentina S.A. s/sum.". Ver Texto, del 31/5/1990, del dictamen del fiscal de Cámara 62073; íd., sala C, in re "Zumpf, Gustavo v. Tucumán 300 S.R.L. s/sum.", del 4/9/1992, del dictamen 66.634.

67. Enrique Welbers S.A. c. Extraktions-technik Gesellschaft s/Ordinario, Sala E, Com. LA LEY, 1989-E, 302.

68. El Diamante S.A. c/Arcor S.A.I.C. s/Ordinario, LD-Textos.

69. Ratificada por la Argentina por ley 22.765. 
este tribunal ha decidido que no altera la naturaleza de convención autónoma de la cláusula arbitral la forma en que se instrumenta, que puede ser contemporánea o no al contrato principal, pero que no depende de este último en cuanto a su validez, a la ley aplicable, ni al juez dotado de jurisdicción para resolver una eventual controversia ${ }^{70}$.

De esta manera, como principio, la cláusula compromisoria constituye un contrato autónomo dentro de otro contrato y que la suerte de este último -así se invoque su nulidad, su inexistencia o su rescisión- no acarrea necesariamente la invalidez del pacto arbitral, en tanto no se pruebe que el consentimiento al arbitraje está viciado de invalidez, cuestión esta última ajena a este conflicto ${ }^{71}$. Esta premisa, que está recogida positivamente en el instrumento universal vigente para la República Argentina en materia de arbitraje internacional -la Convención de Nueva York de 1958-, y en el instrumento regional más reciente -el Acuerdo del MERCOSUR de 1988, ratificado por Ley 24.353-, también rige en arbitraje puramente nacional, tal como lo acepta la doctrina nacional más prestigiosa ${ }^{72}$.

Por otro lado, el principio de competencia/competencia no excluye el control judicial sobre lo decidido por los árbitros acerca de la competencia, sino que la resolución de los árbitros ha de ser previa a cualquier intervención judicial, por lo que cualquier acción para que los jueces se pronuncien sobre el mismo tema no debería suspender el arbitraje $e^{73}$.

Adviértase que, en general, se admite que los tribunales arbitrales puedan resolver sobre su competencia regla kompetenz-kompetenz o principio de competencia de la competencia, ya por vía de excepción, de modo previo emitiendo un laudo parcial sobre el punto o diferir su consideración

70. Cfr. CNCom., sala E, 26/9/1988 en LL 1989-E-304, cit. En Camuzzi Argentina S.A. c/ Sodigas Sur S.A. s/ Sumario, CNCom., sala A, 27/08/1999.

71. "El acuerdo arbitral es independiente del contrato del que forma parte o al cual se refiere. La nulidad o extinción del contrato, no implica necesariamente la del acuerdo arbitral". Causa 2553/10 -I- "Smit International Argentina SA c/ Puerto Mariel SA s/ Tribunal Arbitral" Juzgado n 4, Secretaría no 8 Buenos Aires, 1 de marzo de 2011.

72. Cfr. C. Colomb y C. Kiper, "Código Procesal Civil y Comercial de la Nación Anotado y Comentado", tomo VI, La Ley, 2006, comentario al Art. 742, p. 703; M. E. UZAL, "Solución de controversias en el comercio internacional", ed. Ad-Hoc, 1992, p. 64; R. CAIVANO, "El control judicial en el arbitraje. Apuntes para una futura reforma de la legislación argentina”, La Ley 2008-D-1274 y ss.

73. J. C. RIVERA, El Arbitraje en Argentina a través de la jurisprudencia de su Corte Suprema, Academia Nacional de Derecho 2007 (agosto) 01/01/2007, 1; AR/DOC/3048/2007. 
para el laudo definitivo ${ }^{74}$. Cabe señalar que el hecho de plantear la incompetencia a los propios árbitros por vía de excepción no implica resignar posibilidades o medios de control judicial, aunque los árbitros desestimen la excepción: si declaran su competencia mediante un laudo interlocutorio, esa resolución usualmente es recurrible ante el juez del lugar del arbitraje (Art. 16.3 Ley Modelo de CNUDMI) y los tribunales arbitrales suelen conceder el recurso directo aunque no esté previsto en las reglas del procedimiento aplicable por estimarlo una práctica recomendable; si deciden la cuestión en el laudo definitivo, cabe al excepcionante la posibilidad de solicitar su revisión judicial mediante el recurso de nulidad contra el laudo. Adicionalmente, en uno o en otro caso, la cuestión podrá replantearse, cualquiera haya sido la decisión judicial previa, como argumento para resistir el reconocimiento del laudo en la instancia del exequatur.

\subsection{Medidas cautelares}

El artículo 1655 atribuye a los árbitros la facultad de adoptar, a pedido de cualquiera de las partes, las medidas cautelares que estimen necesarias respecto del objeto del litigio ${ }^{75}$.

Curiosamente el artículo 753 del CPCCN prohíbe expresamente a los árbitros dictar medidas compulsorias y de ejecución, debiendo el panel arbitral, según el texto del citado artículo, recurrir a la autoridad judicial estatal para obtener la ejecución compulsoria. No compartimos este criterio y compartimos parcialmente el del CCyC, pues, si bien faculta a los tribunales arbitrales a dictar medidas cautelares, exige que sean ejecutados por la justicia.

74. Las decisiones judiciales que favorecen la "competencia de la competencia" de los árbitros aun si la validez o existencia del contrato que contiene la cláusula arbitral ha sido impugnada son los siguientes: Corte Suprema, "Otto Franke y Cía. v. Provincia de Buenos Aires s/Constitución de Tribunal Arbitral", (1918), Fallos, t. 128, p. 402; Cámara Federal, "Shore, León c. La Inmobiliaria (Cía. de seguros)", Gaceta del Foro, VII, (marzo-abril 1922), ps. 95-96; CNCom., sala B, july 28, 1954: "Peruzzoti, Arturo A. c. Asociación Argentina de Aves, Conejos y Abejas", Rev. LA LEY, t. 76, ps. 324-327; CNCom., 31 de julio de 1948: "Corporación Cementera Argentina (S. A.) c. Cía. Argentina de Motores Deutz Otto Legítimo S. A.", Rev. LA LEY t. 52, pp. 23-39. Véase H. A. GRIGERA NAÓN, "El arbitraje comercial en el derecho argentino interno e internacional privado", Revista de Derecho Mercantil, Madrid, 163 (1982), ps. 115-134; 117-18; L. PAlACIO, "Derecho Procesal Civil", ps. IX (1988), p. 116. En contra: CNCom., sala B, july 30, 1965: "Hadra y Cía., S. A., Pablo c. Ferriarini, Dardo", Rev. LA LEY 120, pp. 322-325; CNCom., sala B, 30 de setiembre de 1965: "Cimic (Soc. de Resp. Ltda.) c. Silva, Ricardo B.", Rev. LA LEY t. 82, pp. 402-404. "Atorrasagasti A. G. c. Mottide Piazza, R. A. y otros", Rev. LA LEY, t. 91, pp. 59 y siguientes; todos ellos citados por H. A. GRIGERA NAÓN, ob.cit. nota 6).

75. Art. 1655.- Dictado de medidas previas. Excepto estipulación en contrario, el contrato de arbitraje atribuye a los árbitros la facultad de adoptar, a pedido de cualquiera de las partes, las medidas cautelares que estimen necesarias 
Hubiéramos preferido una redacción más moderna, como la del artículo 48 de la Ley Peruana de Arbitraje, donde el tribunal arbitral está facultado para ejecutar, a pedido de parte, sus medidas cautelares, salvo que, a su sola discreción, considere necesario o conveniente requerir la asistencia de la fuerza pública.

Los tribunales arbitrales, en general y salvo disposición en contrario, tienen reconocida competencia para disponer medidas cautelares, pero carecen de fuerza coactiva de poder e imperium para ejecutar la cautelar que hayan dispuesto ${ }^{76}$. Por ello, el artículo 1655 establece que la intervención de los jueces se ceñirá prácticamente a ejecución de las medidas dispuestas por los árbitros, a disponer las que afecten a terceros, y a asistirlos para el cumplimiento coactivo de los actos que así lo requieran. Desde nuestro punto de vista la autoridad judicial no tiene competencia para interpretar el contenido ni los alcances de la medida cautelar.

Ello es así conforme a lo dispuesto en el artículo 19 del Acuerdo de Arbitraje del MERCOSUR ${ }^{77}$ y al artículo 17.h.1. de la ley Modelo de la CNUDMI, sólo que en éste último caso desarrolla toda una serie de procedimientos y establece reglas de conducta con relación a estas medidas.

\subsection{La remisión al arbitraje. La revisión judicial}

El artículo $1656^{78}$ dispone la obligación de las partes de remitir el conflicto a arbitraje, excluyendo a los tribunales judiciales. No es en realidad novedosa la norma pues el ordenamiento positivo argentino -a través

respecto del objeto del litigio. Los árbitros pueden exigir caución suficiente al solicitante. La ejecución de las medidas cautelares y en su caso de las diligencias preliminares se debe hacer por el tribunal judicial. Las partes también pueden solicitar la adopción de estas medidas al juez, sin que ello se considere un incumplimiento del contrato de arbitraje ni una renuncia a la jurisdicción arbitral; tampoco excluye los poderes de los árbitros. Las medidas previas adoptadas por los árbitros según lo establecido en el presente artículo pueden ser impugnadas judicialmente cuando violen derechos constitucionales o sean irrazonables.

76. La convención arbitral inviste a los árbitros de competencia exclusiva sobre el litigio de las partes, aunque, gozan de una competencia estricta y por ende no son autosuficientes, puesto que carecen de la facultad de imponer coactivamente las soluciones a las que arriban y de allí la necesidad de la complementación, cooperación o colaboración por parte del tribunal estatal (CNCom., Sala B, Expediente Nro. 25008/2011 -"Pluris Energy Group Inc. (Islas Virgenes Britanicas Y Otro C/ San Enrique Petrolera S.A. Y Otros S/ Organismos Externos", Del 21/04/2014).

77. "Las medidas cautelares podrán ser dictadas por el tribunal arbitral o por la autoridad judicial competente....

78. Art. 1656. -Efectos. Revisión de los laudos arbitrales. El convenio arbitral obliga a las partes a cumplir lo estipulado y excluye la competencia de los tribunales judiciales sobre las controversias sometidas a arbitraje, excepto que el tribunal arbitral no esté aun conociendo de la controversia, y el convenio parezca ser manifiestamente nulo o inaplicable. En caso de duda ha de estarse a la mayor eficacia del contrato de arbitraje. Los laudos arbitrales que se dicten en el marco de las disposiciones de este Capítulo pueden ser revisados ante la justicia competente por la materia y el territorio 
de la ratificación de la Convención de Nueva York, más precisamente lo dispuesto en su artículo II.3.- ya tenía reconocida esta disposición pro arbitri ${ }^{79}$.

Según el citado artículo los laudos arbitrales pueden ser revisados cuando se invoquen causales de nulidad, total o parcial, por lo que, conforme a la acertada doctrina y jurisprudencia en la materia. El recurso de nulidad no es renunciable.

En consecuencia, la intervención judicial durante el procedimiento arbitral tiene carácter de excepción, encontrándose netamente limitada a las funciones de asistencia y colaboración citadas ${ }^{80}$. Ésta ha sido también la posición adoptada por la mayoría de las legislaciones modernas, tales como la Arbitration Act inglesa, la Ley Alemana de 1998, la Ley Federal Suiza de Derecho Internacional Privado, la Ley Sueca de 1999 y la nueva Ley Española ${ }^{81}$.

En este sentido, la Corte Suprema de Justicia argentina ha resuelto que la administración privada de justicia que implica el arbitraje no es ajena a cierto control judicial, el cual no es susceptible de ser suprimido totalmente, en razón de una exigencia que surge de objetivos constitucionalmente asumidos como el de "promover la justicia" y también de las garantías de la defensa en juicio y de la propiedad y de la ejecutoriedad equivalente a la de una sentencia judicial que el Estado dispensa -cumplidos ciertos recaudos- a los laudos arbitrales. A todo evento, la mayor o menor amplitud del control judicial depende de la misma voluntad que dio origen al arbitraje: de máxima extensión, si las partes cuentan con el recurso de apelación por no haber

cuando se invoquen causales de nulidad, total o parcial, conforme con las disposiciones del presente Código. En el contrato de arbitraje no se puede renunciar a la impugnación judicial del laudo definitivo que fuera contrario al ordenamiento jurídico.

79. El tribunal de uno de los Estados Contratantes al que se someta un litigio respecto del cual las partes hayan concluido un acuerdo en el sentido del presente artículo, remitirá a las partes al arbitraje, a instancia de una de ellas, a menos que compruebe que dicho acuerdo es nulo, ineficaz o inaplicable.

80. La citada autonomía se profundiza aún más en el caso de los arbitrajes internacionales institucionales, en los cuales las entidades administradoras suplen casi todas las funciones judiciales, a excepción de aquéllas que requieren del imperium del cual carecen los árbitros.

81. Ver Arbitration Act, art. 1.c. Similar orientación siguen la Ley Alemana de 1998 (Art. 1032), la Ley Federal suiza de Derecho Internacional Privado (Art. 7), la Ley Sueca de 1999 (Art. 4) y la nueva Ley Española (Art. 7). Ver S. JARVIN, To What Extent are Procedural Decisions of Arbitrators subject to Court Review?, en Improving the Efficiency of Arbitration Agreements and Awards: 40 Years of Application of the New York Convention, ICCA Congress Series No. 9, p. 366. 
renunciado a él o limitado a ciertos ámbitos eminentemente formales en el supuesto de que los contratantes hayan renunciado a aquella apelación y solo dispongan del recurso de nulidad del laudo arbitral ${ }^{82}$.

En esta línea, cabe examinar los supuestos que justifican un planteo de nulidad. Ello ocurre:

a) cuando existe falta esencial de procedimiento, es decir, cuando media un quebrantamiento de principios a punto tal que se evidencie una verdadera inexistencia del debido proceso;

b) cuando se ha fallado fuera de plazo: ello conlleva la pérdida de la jurisdicción arbitral, salvo que la demora hubiera sido consentida expresa o tácitamente por las partes;

c) el pronunciamiento recaído sobre puntos no comprometidos: debe ser entendido como una transgresión al principio de congruencia en el aspecto objetivo, lo cual también es invocable cuando el laudo omite decidir alguna cuestión esencial incluida en el compromiso (citra petita), o resuelve temas extraños a las cuestiones litigiosas sometidas por las partes (extra petita).

Finalmente, también se configura un supuesto de nulidad ante decisiones incompatibles entre sí en su parte dispositiva: cuando un laudo contiene -en el mismo acto- fundamentos contradictorios, de los cuales se desprende una ineficacia intrínseca que impide su ejecución, e invalida el acto arbitral.

Ahora bien, no se entiende realmente la incorporación que hizo la Comisión Bicameral del Congreso respecto a la revisión de los laudos arbitrales. El último párrafo del artículo 1656 es desconcertante: "En el contrato de arbitraje no se puede renunciar a la impugnación judicial del laudo definitivo que fuera contrario al ordenamiento jurídico". De esta manera el legislador desconoce la validez de la renuncia a la impugnación judicial que se hayan pactado en el acuerdo arbitral.

82. CSJN, 17/11/94, C. 950. XXIV. “Color S.A. c. Max Factor Sucursal Argentina s. laudo arbitral s. pedido de nulidad del laudo”. Fallos 317:1527, voto del juez Boggiano. 
La jurisprudencia argentina ha sido clara al resolver que "la mención a que la resolución del tribunal arbitral sería "definitiva e inapelable" importó renunciar al recurso de apelación en los términos autorizados por el Código Procesal en el artículo 741 inc. $5 " 83$. Sin embargo, el legislador prefirió adherir a la muy cuestionable y criticada decisión del máximo tribunal argentino en "Cartellone" 84 .

Es nuestra opinión que, si pretendemos que Argentina sea una sede atractiva para la práctica del arbitraje internacional, la normativa no debería dejar dudas respecto a que todo laudo es definitivo, inapelable y de obligatorio cumplimiento desde su notificación a las partes, salvo que hubiere una causal taxativa de revisión del laudo por nulidad, tal como disponen los artículos 55 y 62 de la Ley Peruana de Arbitraje; y artículos 30 y 31 de la ley ecuatoriana.

\subsection{Arbitraje Institucional-Ad Hoc}

Según el artículo 1657 del CCyC pueden encomendar la administración del arbitraje y la designación de árbitros a asociaciones civiles u otras entidades nacionales o extranjeras cuyos estatutos así lo prevean. Los reglamentos de arbitraje de las entidades administradoras rigen todo el proceso arbitral e integran el contrato de arbitraje. Adviértase que las partes que deciden acudir al arbitraje pueden elegir entre el arbitraje institucional o el arbitraje " $a d$ hoc" o no administrado. En el primer caso, las partes designan a una institución para que administre el arbitraje. En el segundo caso, al elegir el arbitraje "ad hoc" (que se nombra para un arbitraje determinado) fuera del marco institucional, el arbitraje es administrado por los propios árbitros.

Así, se da el arbitraje institucional cuando, en el convenio arbitral, las partes acuerdan que el procedimiento arbitral se ajuste a las reglas de una institución cuya finalidad es la de administrar arbitrajes y, por tanto, renuncian a regular por ellos mismos todos o algunos de los aspectos del arbitraje. La institución no decide la disputa, puesto que ésta constituye responsabilidad exclusiva de los árbitros designados por la institución.

83. "CNCom., Sala C, Buenos Aires, 20 de noviembre de 2008, "Net People Argentina S.A. C. Boca Crece S.A. Y Otro S. Daños y Perjuicios (S. Arbitraje s/ Queja)”.

84. CSJN (1/6/2004) "José Cartellone Construcciones Civiles S.A. c/ Hidroeléctrica Norpatagónica S.A. o Hidronor S.A. s/ proceso de conocimiento". En dicho fallo el máximo tribunal argentino resolvió que no puede lícitamente interpretarse que la renuncia a apelar una decisión arbitral se extienda a supuestos en que 
Se da el arbitraje "ad hoc" cuando las partes acuerdan los diversos aspectos del arbitraje, incluyendo la ley aplicable, las reglas del procedimiento, el método de selección de los árbitros, el idioma, el lugar del arbitraje y las cuestiones a decidir.

El arbitraje es conducido por las partes y el árbitro sin el auxilio de una institución o centro de arbitraje.

Conforme surge de la lectura del citado artículo cabe someterse a las reglas de una institución arbitral sin someterse a la administración de dicha institución.

Consideramos que en caso de falta de designación de una institución arbitral, se entenderá que el arbitraje es ad hoc. Entendemos que la misma regla debe aplicarse cuando exista designación que sea incompatible o contradictoria entre dos o más instituciones, o cuando se haga referencia a una institución arbitral inexistente, o cuando la institución no acepte el encargo, salvo pacto distinto de las partes ${ }^{85}$.

Tampoco la CCyC aclara que en caso de ser institucional el reglamento aplicable es el vigente al momento de su inicio, salvo pacto en contrario ${ }^{86}$.

\subsection{Los árbitros}

Los artículos 1659 al 1665 tratan las reglas relativas a la designación, requisitos, competencia, y obligaciones de los árbitros ${ }^{87}$.

los términos del laudo que se dicte contraríen el orden público, pues no es lógico prever, al formular una renuncia con ese contenido, que los árbitros adoptarán una decisión que incurra en aquel vicio. Entendió el citado tribunal que la apreciación de los hechos y la aplicación regular del derecho son funciones de los árbitros y, en consecuencia, el laudo que dicten será inapelable en esas condiciones, en cambio, su decisión podrá impugnarse judicialmente cuando sea inconstitucional, ilegal o irrazonable (Fallos: 292:223).

85. Ver artículo 7.3. Ley Peruana de Arbitraje.

86. Ver artículo 7.4. Ley Peruana de Arbitraje.

87. Art. 1659.- Designación de los árbitros. El tribunal arbitral debe estar compuesto por uno o más árbitros en número impar. Si nada se estipula, los árbitros deben ser tres. Las partes pueden acordar libremente el procedimiento para el nombramiento del árbitro o los árbitros.

A falta de tal acuerdo:

a) en el arbitraje con tres árbitros, cada parte nombra un árbitro y los dos árbitros así designados nombran al tercero. Si una parte no nombra al árbitro dentro de los treinta días de recibido el requerimiento de la otra parte para que lo haga, o si los dos árbitros no consiguen ponerse de acuerdo sobre el tercer árbitro dentro de los treinta días contados desde su nombramiento, la designación debe ser hecha, a petición de una de las partes, por la entidad administradora del arbitraje o, en su defecto, por el tribunal judicial; 
En lo atinente a la composición del tribunal arbitral el CCyC brinda una adecuada respuesta a tres interrogantes básicos: i) el número de árbitros; ii) la forma en que deberán ser elegidos; y iii) las calificaciones (e inclusive nacionalidades) que deberán ser tomadas en cuenta.

\section{En la selección de los árbitros recae gran parte de la suerte que tendrá} el proceso arbitral ${ }^{88}$. Ya sea en un arbitraje $a d-h o c^{89}$ como en uno institucional ${ }^{90}$, las partes deberán prestar debida atención a la calidad de los profesionales que ejercerán la tarea de resolver la disputa.

b) en el arbitraje con árbitro único, si las partes no consiguen ponerse de acuerdo sobre la designación del árbitro, éste debe ser nombrado, a petición de cualquiera de las partes, por la entidad administradora del arbitraje o, en su defecto, por el tribunal judicial. Cuando la controversia implica más de dos partes y éstas no pueden llegar a un acuerdo sobre la forma de constitución del tribunal arbitral, la entidad administradora del arbitraje, o en su defecto, el tribunal judicial debe designar al árbitro o los árbitros.

Art. 1660.- Calidades de los árbitros. Puede actuar como árbitro cualquier persona con plena capacidad civil. Las partes pueden estipular que los árbitros reúnan determinadas condiciones de nacionalidad, profesión o experiencia. Art. 1661.- Nulidad. Es nula la cláusula que confiere a una parte una situación privilegiada en cuanto a la designación de los árbitros.

Art. 1662.- Obligaciones de los árbitros. El árbitro que acepta el cargo celebra un contrato con cada una de las partes y se obliga a:

a) revelar cualquier circunstancia previa a la aceptación o que surja con posterioridad que pueda afectar su independencia e imparcialidad;

b) permanecer en el tribunal arbitral hasta la terminación del arbitraje, excepto que justifique la existencia de un impedimento o una causa legítima de renuncia;

c) respetar la confidencialidad del procedimiento;

d) disponer de tiempo suficiente para atender diligentemente el arbitraje;

e) participar personalmente de las audiencias;

f) deliberar con los demás árbitros;

g) dictar el laudo motivado y en el plazo establecido.

En todos los casos los árbitros deben garantizar la igualdad de las partes y el principio del debate contradictorio, así como que se dé a cada una de ellas suficiente oportunidad de hacer valer sus derechos.

Art. 1663.- Recusación de los árbitros. Los árbitros pueden ser recusados por las mismas razones que los jueces de acuerdo al derecho de la sede del arbitraje. La recusación es resuelta por la entidad administradora del arbitraje o, en su defecto, por el tribunal judicial. Las partes pueden convenir que la recusación sea resuelta por los otros árbitros. Art. 1664.- Retribución de los árbitros. Las partes y los árbitros pueden pactar los honorarios de éstos o el modo de determinarlos. Si no lo hicieran, la regulación se hace por el tribunal judicial de acuerdo a las reglas locales aplicables a la actividad extrajudicial de los abogados.

88. Un procedimiento arbitral es tan bueno como la calidad de los árbitros que lo conducen. P. SANDERS, Quo Vadis Arbitration? Sixty Years of Arbitration Practice, Kluwer Law International, The Hague, Netherlands, 1999, p. 224.

89. En los procesos arbitrales "libres" o ad-hoc las partes no están sometidos a ningún mecanismo prefijado de administración y control. Las partes tienen, por consiguiente, que determinar las reglas procesales aplicables al caso, sea mediante la incorporación de reglas de procedimiento diseñadas por ellas o adoptando el de alguna ley nacional o reglas "modelo" o "tipo" existentes o autorizando a los árbitros a establecer sus propios procedimientos. Va de suyo que en esta clase de juicios, de producirse cuestiones procesales que las partes no logren solucionar de común acuerdo, además de las que requieran del respaldo del "imperium" judicial, deberá recurrirse para dirimir esas diferencias a la justicia o, donde ello cupiera, a los organismos estatales facultados a esos efectos (J. O'FARRELL, Arbitraje Internacional, solución de futuro, La Ley 1992-C, 803).

90. Cuando el arbitraje es regulado a través de una institución especializada (por e.j. la Cámara de Comercio Internacional), éstas mismas proveen a las partes de listas de profesionales reconocidos en sus cualidades profesionales y humanas. Estas listas proporcionan mayor seguridad a las partes a la hora de elegir la personas idóneas para 
No se mencionan incompatibilidades ${ }^{91}$ para ser árbitro y sólo se requiere plena capacidad civil, aunque las partes pueden convenir que los árbitros reúnan determinadas condiciones de nacionalidad, profesión o experiencia (Cfr. artículo 1660 $)^{92}$.

Ahora bien, consideramos evidente que en los casos de arbitraje de derecho los árbitros deben ser abogados, tal como dispone por ejemplo el artículo $3^{\circ}$, último párrafo, de la Ley de Mediación y Arbitraje de Ecuador.

Por su parte, la ley de Arbitraje de Perú93 establece condiciones para ser árbitro. Por ejemplo, en el arbitraje internacional no se requiere ser abogado y, en el arbitraje doméstico, cuando se solicite la calidad de abogado, éste no debe pertenecer a ninguna asociación o gremio de abogados nacional o internacional ${ }^{94}$.

Respecto a la posibilidad que los jueces y funcionarios del Poder Judicial sean nombrados árbitros, nada dispone el CCyC. Se modifica lo dispuesto por el Código Procesal Civil y Comercial de la Nación, donde se prohíbe, bajo pena de nulidad, que estos funcionarios públicos acepten el nombramiento de árbitro o amigables componedores, salvo que en el juicio fuese parte la Nación o una provincia (Art. 765). Por su parte, conforme la citada normativa, los árbitros designados por el juzgado podrán ser recusados por las mismas causas que los jueces (Art. 746) y aquellos nombrados de común acuerdo por las partes serán recusados únicamente por causas posteriores al nombramiento. Los árbitros no podrán ser recusados sin causa y sólo serán removidos por consentimiento de las partes y decisión del juez. El procedimiento quedará suspendido mientras no se haya decidido sobre la recusación (Art. 747).

asumir la función de árbitro. Inclusive muchas de ellas proporcionan capacitación y entrenamiento a dichos profesionales, ya que en el desempeño de éstos se encuentra depositado el prestigio de la institución. Se entiende por arbitraje institucional aquel administrado por un centro especializado en la materia y sujeto a un reglamento de cuyo cumplimiento se encarga dicha institución (Cfr. F. MANTILla SERRANO. La Corte Internacional de la CCI, La Ley, 1996-D, 1567).

91. Conforme el artículo 14(II). Los funcionarios judiciales, miembros del Poder Legislativo, servidores públicos, funcionarios del Ministerio Público y operadores de bolsa, se encuentran, impedidos de actuar como árbitros, bajo pena de nulidad del laudo, sin perjuicio de la responsabilidad que les pueda corresponder por aceptar una designación arbitral.

92. El artículo 36 de la Ley de Conciliación, Mediación y Arbitraje de El Salvador dispone que no podrán actuar como árbitros quienes tengan con las partes o sus apoderados alguna de las causas de excusa y recusación que establecen las reglas procesales. Tampoco podrán actuar como árbitros los jueces, magistrados, fiscales, diputados de la Asamblea Legislativa, funcionarios públicos y los empleados del Órgano Judicial.

93. Decreto Legislativo $\mathrm{N}^{\circ} 1071$ de 2008.

94. Decreto Legislativo $\mathrm{N}^{\circ}$ 1071. Artículo $20^{\circ}$ - Capacidad Pueden ser árbitros las personas naturales que se hallen 
Ahora bien, según el artículo 1663 los árbitros pueden ser recusados por las mismas razones que un juez de acuerdo a la ley de la sede del arbitraje, debiendo ser resuelta por la institución arbitral o el tribunal judicial, según sea institucional o ad hoc.

Todo reglamento de arbitraje establece en qué casos y bajo qué tipo de procedimiento se podrá recusar a un miembro del tribunal arbitral ${ }^{95}$. Si bien resulta imposible enumerar la totalidad de las causales de recusación de árbitros que contemplan los diferentes reglamentos existentes, podemos enunciar las siguientes: a) interés directo en el asunto; b) existencia de una relación económica o subordinación profesional con una de las partes; c) relación anterior de subordinación profesional y/o económica con una de las partes; d) imparcialidad o expresión de opinión previa; y e) actuación como árbitro en procesos similares.

Adviértase que la normativa menciona simplemente que es obligación de los árbitros dictar el laudo en forma motivada y en el plazo establecido. Parece contemplar solamente al laudo final y definitivo y no a los laudos parciales o a la bifurcación de arbitrajes, una práctica muy común en el arbitraje moderno, y que requerirá de tantos laudos parciales como estime necesarios el tribunal arbitral.

en el pleno ejercicio de sus derechos civiles, siempre que no tengan incompatibilidad para actuar como árbitros. Salvo acuerdo en contrario de las partes, la nacionalidad de una persona no será obstáculo para que actúe como árbitro. Artículo $21^{\circ}$.- Incompatibilidad Tienen incompatibilidad para actuar como árbitros los funcionarios y servidores públicos del Estado peruano dentro de los márgenes establecidos por las normas de incompatibilidad respectivas. Artículo $22^{\circ}$.- Nombramiento de los árbitros 1 . En el arbitraje nacional que deba decidirse en derecho, se requiere ser abogado, salvo acuerdo en contrario. En el arbitraje internacional, en ningún caso se requiere ser abogado para ejercer el cargo.

95. Conforme el artículo 12 de la Ley Modelo, la recusación deberá estar motiva en que: 1) La persona a quien se comunique su posible nombramiento como árbitro deberá revelar todas las circunstancias que puedan dar lugar a dudas justificadas acerca de su imparcialidad o independencia. El árbitro, desde el momento de su nombramiento y durante todas las actuaciones arbitrales, revelará sin demora tales circunstancias a las partes, a menos que ya les haya informado de ellas; 2) Un árbitro sólo podrá ser recusado si existen circunstancias que den lugar a dudas justificadas respecto de su imparcialidad o independencia, o si no posee las cualificaciones convenidas por las partes. Una parte sólo podrá recusar al árbitro nombrado por ella, o en cuyo nombramiento haya participado, por causas de las que haya tenido conocimiento después de efectuada la designación.

Por su parte, el artículo 13 dispone el procedimiento de recusación: 1) Sin perjuicio de lo dispuesto en el párrafo 3) del presente artículo, las partes podrán acordar libremente el procedimiento de recusación de los árbitros. 2) A falta de tal acuerdo, la parte que desee recusar a un árbitro enviará al tribunal arbitral, dentro de los quince días siguientes a aquel en que tenga conocimiento de la constitución del tribunal arbitral o de cualquiera de las circunstancias mencionadas en el párrafo 2) del artículo 12, un escrito en el que exponga los motivos para la recusación. A menos que el árbitro recusado renuncie a su cargo o que la otra parte acepte la recusación, corresponderá al tribunal arbitral decidir sobre ésta; 3) Si no prosperase la recusación incoada con arreglo al procedimiento acordado por las partes o en los términos del párrafo 2) del presente artículo, la parte recusante podrá pedir, dentro de los treinta días siguientes al recibo de la notificación de la decisión por la que se rechaza 
Deja asimismo dudas respecto a la posibilidad de que un árbitro se niegue a firmar el laudo, donde por lo general las legislaciones más modernas en la materia suelen contemplar que, en caso que haya más de un árbitro, bastarán las firmas de la mayoría de los miembros o sólo la del presidente, según corresponda, siempre que se manifiesten las razones de la falta de una o más firmas ${ }^{96}$. Otras legislaciones' como la boliviana, disponen que el árbitro que se niegue a la firma del laudo será sancionado con la pérdida de sus honorarios, al igual que el árbitro disidente que no fundamente por escrito las razones de su discrepancia o voto particular ${ }^{97}$.

La competencia del árbitro se extingue con el dictado del laudo definitivo, salvo en lo referente a resoluciones aclaratorias o complementarias. En ese sentido es similar al artículo 60 de la ley peruana ${ }^{98}$.

Nada dispone sobre la responsabilidad por los daños y perjuicios que causaren por dolo o culpa inexcusable ya sea de los árbitros como de la institución arbitral, en caso de incumplimiento de las obligaciones a su cargo ${ }^{99}$.

\section{Conclusión}

A lo largo de esta exposición hemos considerado, en forma introductoria, la normativa que será efectiva a partir del mes de agosto en la República Argentina, mediante la cual entendemos ha sido receptada la actual tendencia a favor de una legislación moderna en materia arbitral,

la recusación, al tribunal u otra autoridad competente conforme al artículo 6, que decida sobre la procedencia de la recusación, decisión que será inapelable; mientras esa petición esté pendiente, el tribunal arbitral, incluso el árbitro recusado, podrán proseguir las actuaciones arbitrales y dictar un laudo.

96. Ver sobre particular el artículo 27 de la Ley de Mediación y Arbitraje de Ecuador.

97. Artículo 15(III). Ley 1770.

98. Artículo $60^{\circ}$.- Terminación de las actuaciones. 1. Las actuaciones arbitrales terminarán y el tribunal arbitral cesará en sus funciones con el laudo por el que se resuelva definitivamente la controversia y, en su caso, con las rectificaciones, interpretaciones, integraciones y exclusiones del laudo, sin perjuicio de lo dispuesto en el artículo $67^{\circ}$.

99. Ver sobre el particular el artículo 32 de la Ley Peruana de Arbitraje; el artículo 15(II) de la Ley 1770 de Bolivia y el artículo 40 Ley de Conciliación, Mediación y Arbitraje de El Salvador. Respecto a la responsabilidad que le corresponde a los árbitros, el Art. 31.1. del Reglamento de la London Court of International Arbitration dispone que: "Ningún miembro de la LCIA (incluidos su Presidente, Vicepresidente y miembros individuales), su Secretario o Secretario en funciones, árbitro o perito del tribunal arbitral serán responsables ante ninguna parte de acto u omisión alguna surgida de un arbitraje instruido al amparo de este Reglamento, salvo que la parte afectada demuestre que dicho acto u omisión constituyen un acto ilegal, consciente y deliberadamente cometido por el Organismo o persona que dicha parte considera responsable:" 
donde se destaca la limitada intervención judicial en el arbitraje, el principio de autonomía del proceso arbitral y el de Kompetenz-Kompetenz. Sin embargo, debemos señalar que la legislación analizada deja algunas dudas respecto a la validez de las renuncias acordadas entre las partes, así como deja de lado el tratamiento de ciertas cuestiones esenciales de las consecuencias del arbitraje, como el proceso de ejecución de laudos arbitrales y los efectos centrales de los laudos (carácter de cosa juzgada, ejecutividad como sentencia, auxilio judicial y recursos posibles).

Dicho esto, es nuestra opinión que es innegable el avance en la decisión política legislativa argentina favorable al arbitraje por medio de la incorporación de normas necesarias para su adecuación a la práctica arbitral. 